\title{
PROCESSOS DE CRIAÇÃO POÉTICA EM “POEMAS AOS HOMENS DO NOSSO TEMPO", DE HILDA HILST
}

\author{
lara de Oliveira \\ Mestranda em Estudos Literários pela Universidade Federal de Goiás (UFG) \\ Bolsista da Coordenação de Aperfeiçoamento de Pessoal de Nível Superior (CAPES) \\ iaraoliveiraport@gmail.com
}

\section{RESUMO}

O livro Júbilo, memória e noviciado da paixão (1974) é constituído por poemas que, em sua maioria, versam acerca do amor e erotismo. No entanto, "Poemas aos homens do nosso tempo" encerra o referido livro com uma voz lírica destoante das anteriores, conforme demonstra certa preocupação com o fazer poético e evidencia o contexto da ditadura militar com acentuada criticidade. Em vista disso, o objetivo deste artigo consiste em analisar como o contexto ditatorial brasileiro emerge nesse poema e compreender a maneira que a subjetividade lírica concebe o papel do poeta e da poesia em determinada conjuntura política, além de observar em que medida essa concepção tornar-se-á a motivação de criação escrita. Isso, através de uma leitura analítica do poema em questão. Para aprofundar as discussões propostas, a pesquisa recorre aos estudos de Theodor Adorno (2003), Giorgio Agamben (2009), Mikhail Bakhtin (1997), Fayga Ostrower (2009), entre outros.

Palavras-chave: criação, lírica, sociedade.

\section{RESUMEN}

El libro Júbilo, memoria y noviciado de la pasión (1974) está constituido por poemas que, en su mayoría, versan acerca del amor y el erotismo. Sin embargo, "Poemas a los hombres de nuestro tiempo", encierra el referido libro con una voz lírica destoante de las anteriores, como demuestra cierta preocupación por el hacer poético y evidencia el contexto de la dictadura militar con acentuada criticidad. En vista de ello, el objetivo de este artículo consiste en analizar cómo el contexto dictatorial brasileño emerge en ese poema y comprender la manera que la subjetividad lírica concibe el papel del poeta y de la poesía en determinada coyuntura política, además de observar en qué medida esa concepción, se dará la motivación de creación escrita. Esto, a través de una lectura analítica del poema en cuestión. Para profundizar las discusiones propuestas, la investigación recurre a los estudios de Theodor Adorno (2003), Giorgio Agamben (2009), Mijaíl Bakhtin (1997), Fayga Ostrower (2009), entre otros.

Palabras clave: creación, lírica, sociedad. 


\section{Introdução}

O amor, o erotismo, o desejo, as referências religiosas e míticas são constantes da lírica hilstiana, sobretudo no livro Júbilo, memória e noviciado da paixão (1974). Esse é o primeiro livro de poesias escritas por Hilda Hilst após se enveredar em escritas prosaicas. A escolha de retornar à escrita lírica constitui um valor da mentalidade criativa, dado que nele é apresentada ao leitor uma subjetividade lírica feminina que se mostra lúcida do seu ato criador ao estabelecer diálogos com a poesia mélica e trovadoresca e por, muitas vezes, se nomear como poeta. Em meio a isso, a voz lírica se manifesta por meio de um canto ardente e suplicante recorrendo a diálogos com o sujeito amado, o qual não corresponde aos seus anseios amorosos e dela está distanciado, ocasionando, assim, inquietação e melancolia nessa mulher. É como se determinadas questões a serem ditas só coubessem na versificação e na justeza do poema.

A manifestação do sujeito pela arte indica uma tomada de consciência de si e uma tomada de consciência do mundo. Nesse sentido, Nelly Novaes Coelho, no artigo $A$ literatura feminina no Brasil contemporâneo, ao apontar o surgimento de uma "nova" mulher no entremeio dos anos 70 e 80 e os seus fatores, destaca:

o amadurecimento crescente de sua consciência crítica que a força a se posicionar, não só em relação à falência do modelo-decomportamento feminino, como também quanto à interdependência existente ou imposições do contexto sócio-cultural em que essa criação surge (COELHO, 1991, p. 95).

Será em vista dessa consciência crítica em constante ascendência que a subjetividade lírica permeante de Júbilo, memória e noviciado da paixão (1974) conferirá 
certa "pausa" na criação/produção de sua lírica amorosa para realizar uma leitura corrosiva de seu próprio tempo, de seu próprio contexto sócio-histórico e político. O que, consequentemente, significa um valor dos procedimentos de escrita e substancia a poesia de maior participação no universal a partir de uma expressão individual.

A mentalidade criativa de Hilda Hilst é contingenciada a criar "Poemas aos homens do nosso tempo" diante da barbárie do governo militar em que, inevitavelmente, estava circunscrita. Isso configura um valor de mundo emergindo em sua poesia, o qual impulsiona o voo do poema em verso livre, sendo esse também uma escolha carregada de valor social e literário. Ambos os valores instrumentalizam a criação e são decisivos procedimentos criativos. Além de ser uma atitude de resistência, de posicionamento axiológico e, sobretudo, de coragem em face de toda repressão e perseguição praticada pelo regime militar - atitudes essas que consolidaram uma das formas de resguardar o ideário político e governamental militar em vigência.

Assim, os objetivos do presente artigo consistem em analisar como o contexto ditatorial brasileiro emerge no último conjunto de poemas deste livro e compreender a forma como o eu lírico concebe o papel do poeta e da poesia em dada conjuntura política, além de depreender em que medida essa concepção se tornou a motivação de criação escrita. Importante ressaltar que esta proposta de leitura e análise não se debruçará tão somente nos poemas mais representativos aos objetivos expostos, mas, também, aos aspectos que envolvem a realidade histórica, social, política e econômica envolventes da publicação do referido poema, a fim de mapear possíveis elementos que influenciaram a tessitura literária da poetisa brasileira.

No primeiro momento do artigo, serão realizadas algumas considerações acerca dos aspectos precedentes à criação escrita, tais como as possíveis motivações, as 
influências e as circunstâncias de violência (verbal, física e simbólica) da ditadura militar instaurada no Brasil em 1964. No segundo momento, o poema será analisado à guisa de compreender como a subjetividade lírica concebe a poesia e a tarefa que caberia aos poetas - conscientes de seus papeis - em vista das referidas contingências sociais e políticas.

\section{A constituição da mentalidade criativa}

O contexto de valores em que se realiza e é pensada determinada obra literária não se reduz apenas ao âmbito do literário, uma vez que a obra de arte e o artista fazem parte de um contexto de mundo que é político. Por isso, observar aquilo que antecede os procedimentos poéticos de escrita implica observar, também, os valores da época em que a obra é produzida. Para Fayga Ostrower "o criar só pode ser visto num sentido global, com um agir integrado em um viver humano. De fato, criar e viver se interligam" (OSTROWER, 2009, p. 5). É entre o viver imersa no regime militar brasileiro e a sensibilidade/criticidade de seu criar poético que Hilda Hilst dotará seus versos de um canto vigoroso e imperativo em dissonância à postura apática dos demais homens de sua sociedade.

A expressão individual de "Poemas aos homens do nosso tempo" carrega em seus enunciados as vozes de outros poetas, isto é, os versos desse poema de Hilda Hilst são marcados pela representatividade da coletividade de artistas. E, essa expressão consiste em um contínuo resvalar do eu empírico no eu lírico. Nesse sentido, Mikhail Bakhtin

afirmou que "viver significa ocupar uma posição axiológica, significa firmar-se axiologicamente em cada momento da vida" (BAKHTIN, 2011, p. 174). É preenchendo um 
posicionamento axiológico próprio do viver que Hilda Hilst, em seus procedimentos de criação escrita, expressará através da subjetividade lírica do poema as preocupações que circundam o seu eu empírico no que concerne à produção artística e às manifestações de opiniões e posicionamentos divergentes ao do governo em regime militar, as quais desencadearam em presos políticos: morte, tortura e exílio.

Essa consciência crítica acompanhada de uma leitura corrosiva da realidade contemporânea impulsiona a criação poética de Hilst a ponto de se propor a versificar ardentemente acerca da repressão e do silenciamento dos artistas, dos poetas e, consequentemente, da poesia. Por outro lado, Theodor W. Adorno declara que no poema lírico a sedimentação da relação entre o sujeito e a objetividade deve ocorrer de modo involuntário para que se aproxime da perfeição:

em cada poema lírico devem ser encontrado, no médium do espírito subjetivo que se volta sobre si mesmo, os sedimentos da relação histórica do sujeito com a objetividade, do indivíduo com a sociedade. Esse processo de sedimentação será tanto mais perfeito quanto menos a composição lírica tematizar a relação entre o eu e a sociedade, quanto mais involuntariamente essa relação for cristalizada, a partir de si mesma, no poema (ADORNO, 2003, p. 72).

E, embora a tessitura do poema, aparentemente, não tenha ocorrido de forma puramente espontânea, involuntária, a subjetividade lírica encontra na linguagem, na arte da palavra, o meio para expressar aquilo que sua mentalidade criativa vinha sendo contingenciada a criar: "a linguagem estabelece a mediação entre lírica e sociedade no que há de mais intrínseco" (ADORNO, 2003, p. 74). Assim, o canto ardente da poetisa metaforizado em "pássaro-palavra" alçará voo em direção à vida e, sobretudo, aos homens "comuns" e aos homens que, de certa maneira, participam e colaboram com as 
contingências governamentais da ditadura, todos esses, contemporâneos de Hilda e de sua criação lírica.

É oportuno elucidar que a publicação deste poema data de 1974, período no qual militares regiam o governo e Emílio Médici foi nomeado como presidente da república, o que provocou resposta e resistência de movimentos opositores. Por essa razão, os dominadores intensificaram a tortura e a repressão como modo de neutralizar e erradicar toda forma de oposição. No entanto, como "a lírica se mostra mais profundamente assegurada, em termos sociais, ali onde não fala conforme o gosto da sociedade" (ADORNO, 2003, p. 74) esse poema inicia com uma evocação de "senhoras e senhores", seguido de uma ordem para que direcionem seus olhares aos poetas, à voz que vos falam. A subjetividade lírica demonstra aguda inquietação e ordena um movimento que não parece ser comum aos sujeitos a quem se dirige: olhar àqueles que poetizam o mundo e quiçá empreender leituras dos respectivos poemas. Por isso, a voz lírica convoca-os para esclarecer e evidenciar os desígnios dos poetas, os quais consistem em "repensar o pensar", indicando, assim, a consciência crítica que, praticamente, integra a fisiologia dos poetas, os quais a voz representa no seu cantar.

É possível inferir que o sujeito lírico é um poeta deste "mundo caduco" a partir dos marcadores de primeira pessoa do plural, de sua inclusão em seu próprio discurso imbuído de representatividade. De acordo com Bakhtin, "o autor deve ser entendido, antes de tudo, a partir do acontecimento da obra como participante dela, como orientador autorizado do leitor" (1997, p. 191). Sendo assim, voz lírica conduz o seu leitor, o seu endereçado a romper os limites da neblina que envolve os seus olhos para, de certo modo, denunciar que por trás da tarefa que lhes cabe, quando cai a noite, há a falsificação dos seus rostos, mudam suas faces, pois tratam-se rostos que pensam 
criticamente o tempo, a sociedade e a política, na contracorrente e, por isso, oferecem riscos ao poder em vigência:

I

homenagem a

Alexander Solzhenitsyn

Senhoras e senhores, olhai-nos.

Repensamos a tarefa de pensar o mundo.

E quando a noite vem

Vem a contrafação dos nossos rostos

Rosto perigoso, rosto-pensamento

Sobre os vossos atos.

A muitos os poetas lembrariam

Que o homem não é para ser engolido

Por vossas gargantas mentirosas.

E sempre um ou dois dos vossos engolidos

Deixarão suas heranças, suas memórias

A IDEIA, meus senhores

E essa é a mais brilhosa

Do que o brilho fugaz de vossas botas.

[...]

(HILST, 2017, p. 286).

Os poetas expõem seus rostos audaciosos e apontam o motivo pelo qual são considerados perigosos: lembrar, por meio da poesia, que o homem não deve se deixar conduzir pelas vozes das gargantas mentirosas. Eles também apontam que os que são engolidos não são totalmente apagados, pois deixam suas marcas no tempo, na história e que deles não esquecerão. Esses versos tematizam como o regime militar - desde 1964 até o ano da primeira publicação desses poemas, 1974 - atinge os homens de sua sociedade. Para Giorgio Agamben "contemporâneo é, justamente, aquele que sabe ver essa obscuridade, que é capaz de escrever mergulhando a pena nas trevas do presente" 
(AGAMBEN, 2009, p. 63). O que é uma habilidade particular de Hilst, dado que sua criação poética resvala no seu posicionamento crítico empírico, frente ao autoritarismo, à repressão e, sobretudo, às tentativas de silenciamento e apagamento das produções literárias brasileiras que, de algum modo, faziam parte do movimento de resistência.

Para Fayga Ostrower "ao criar, ao ordenar os fenômenos de determinada maneira e ao interpretá-los, parte-se de uma motivação interior. A própria motivação contém intensidades psíquicas. São elas que propõem e impelem o fazer" (OSTROWER, 2009, p. 28). De fato, é notável que a motivação da elaboração escrita de "Poemas aos homens do nosso tempo" parte da necessidade de defender com as garras do lirismo e com as labaredas do canto a relevância da poesia para o mundo e para os homens, como é possível observar nos seguintes versos:

$[\ldots]$

Cantando amor, os poetas na noite

Repensam a tarefa de pensar o mundo.

E podeis crer que há muito mais vigor

No lirismo aparente

No amante Fazedor da palavra

Do que na mão que esmaga

A IDEIA é ambiciosa e santa.

E o amor dos poetas pelos homens

É mais vasto

Do que a voracidade que vos move.

E mais forte há de ser

Quanto mais parco

Aos vossos olhos possa parecer

(HILST, 2017, p. 286). 
A subjetividade lírica defende que a lírica e o "Fazedor da palavra" tem muito mais valor e mais vigor do que a coibição feita por esses senhores, pelos militares governantes e seus respectivos apoiadores, posto que os poetas amam os homens de sua sociedade com tamanha impetuosidade, a ponto de ser mais intenso do que a violência praticada ao esmagarem e engolirem a consciência desses homens. Para encerrar esses versos, a voz lírica concede um aviso aos senhores, com os quais dialoga: quanto mais considerarem inofensivas ao regime ditatorial a literatura emergida de dado contexto sócio-histórico, mais ela haverá de ser ofensiva e resistente. Esse verso possibilita inferir, por exemplo, como as publicações infantis e juvenis carregadas de metáforas que retrataram o contexto ditatorial, como O reizinho mandão (1982) e O rei que não sabia de nada (1980), de Ruth Rocha, podem significar essa aparente "inofensividade".

Os poetas dos anos 70 são representados por uma voz lírica que assevera incisivamente o fato de que a poesia não sucumbirá às ordens autoritárias e sequer se submeterá aos anseios para que sejam auxiliares na legitimação do referido governo: "por isso ser contemporâneo é, antes de tudo, uma questão de coragem: porque significa ser capaz não apenas de manter fixo o olhar no escuro da época, mas também de perceber nesse escuro uma luz que, dirigida para nós, distancia-se infinitamente de nós" (AGAMBEN, 2009, p. 65). No contexto ditatorial, o distanciamento da luz resultava de articulações a fim de manipular o processo criativo dos artistas brasileiros e a mentalidade dos leitores.

Com relação a isso, Maria José de Rezende afirma em seu estudo que: "o órgão de educação cultural e moral, o IPES, através de seu Grupo de Opinião Pública, incumbia-se de divulgar uma denominada, por seus membros, literatura democrática para fazer frente à literatura marxista que, segundo eles, enchiam as livrarias" (REZENDE, 2013, p. 67). Isso 
retrata os meios utilizados pelo regime militar para controlar o mercado literário e editorial, na medida em que selecionava aquilo que seria "adequado" e deveria ser disponibilizado para venda nas livrarias, bem como aquilo que poderia ser publicado pelas editoras. A intenção por trás disso consistia em restringir as possibilidades de difusão do conhecimento, do pensamento e da manifestação artística divergente. Tudo isso, para colaborar com o desenvolvimento da consciência coletiva de apoio à ditadura militar por falta/restrição à informação crítica, diversificada e não manipulada.

Os valores de uma determinada época, em linhas gerais, constituem-se como "formas" do processo criativo de um artista. Certamente, a mentalidade criativa de Hilda Hilst é constituída e contingenciada a criar devido ao fato de ver e vivenciar atitudes governamentais - imbuídas de barbáries, visando silenciar o seu canto e o canto de outros poetas do seu tempo. Canto esse que é indissociável do poeta enquanto sujeito social, enquanto homem, uma vez que as palavras e os versos são o seu viver, são os seus modos de (re)organizar o mundo no qual está circunscrito. Em discordância dessas ações políticas, a poeta partirá do que tenta ser violado - a poesia - para reagir contra o movimento conservador e para incisivamente criticá-lo. Nesse sentido, de acordo com Lev Vygotsky:

no movimento mais íntimo e pessoal do pensamento, do sentimento, etc., o psiquismo de um indivíduo particular seja efetivamente social e socialmente condicionado. Não é nada difícil mostrar que o psiquismo de um indivíduo particular é justamente o que constitui o objeto da psicologia social (VYGOTSKY, 1999, p. 14).

Desse modo, é preciso considerar que sendo o psiquismo de um indivíduo particular e social ao mesmo tempo, não há possibilidade da poesia emergida do 
psiquismo de um poeta seja de natureza distinta. Em outras palavras, não existe a probabilidade da poesia não ser uma junção do individual e do social, dado que essa relação está intrinsecamente relacionada. Assim, Adorno ratifica tal percepção ao enfatizar que "Não apenas o indivíduo é socialmente mediado em si mesmo, não apenas seus conteúdos são sempre, ao mesmo tempo, também sociais, mas, inversamente, também a sociedade configura-se e vive apenas em virtude dos indivíduos, dos quais ela é a quintessência" (ADORNO, 2003, p. 75). Logo, o indivíduo e a linguagem são mediados pelo social e vice-versa, além disso, a lírica e a sociedade se interpenetram e, somente assim, são apanhados elementos do tempo histórico.

Algo semelhante ocorre com a tradição literária, pois se o poeta é leitor de grandes obras da cultura humana, as quais são compostas de valores literários e de valores de determinados tempos históricos, é por meio dessa tradição e desses valores que se constitui a sua formação enquanto artista. Em razão disso, a composição da forma de "Poemas aos homens do nosso tempo" é uma peculiaridade imbuída de valores tanto quanto o conteúdo. Exemplo disso são as escolhas dos versos livres, do constante enjambement, e das marcações em caixa alta, as quais, em outros contextos históricos e literários, poderiam ser consideradas incapacidade de elaboração poética e estética. Entretanto, no contexto de 1974, a escolha valorativa dessa forma para carregar a materialidade da linguagem expressa pela subjetividade lírica colabora, em grande medida, para significar o desejo de liberdade, de se livrar das amarras do autoritarismo e da barbárie.

Com relação a isso, Bakhtin enfatiza que "o autor visa ao conteúdo, enforma-o e o conclui usando para isso um determinado material, no nosso caso verbalizado, subordinando esse material ao seu desígnio artístico, isto é, à tarefa de concluir uma dada 
tensão ético-cognitiva" (BAKHTIN, 1997, p. 177). Em "Poemas aos homens do nosso tempo" a denominada "tensão ético-cognitiva" consiste na tentativa das forças de ferro em impedirem as palavras poéticas de voarem livremente pelo céu e percorrerem as bocas dos homens, como evidenciado no poema a seguir:

$\mathbf{X}$

Amada vida:

Que essa garra de ferro

Imensa

Que apunhala a palavra

Se afaste

Da boca dos poetas.

PÁSSARO-PALAVRA

LIVRE

VOLÚPIA DE SER ASA

NA MINHA BOCA.

Que essa garra de ferro Imensa

Que me dilacera

Desapareça

Do ensolarado roteiro

Do poeta.

PÁSSARO-PALAVRA

LIVRE

VOLÚPIA DE SER ASA

NA MINHA BOCA.

Que essa garra de ferro

Calcinada

Se desfaça

Diante da luz

Intensa da palavra.

PALAVRA-LIVRE

Volúpia de ser pássaro

Amada vertiginosa. 
Asa.

(HILST, 2017, p. 293).

Nesse poema, a subjetividade lírica endereça o seu canto à vida, e evidencia o seu desejo não mais sexual e amoroso como nos conjuntos de poemas anteriores a este no livro, mas de que a garra de ferro - metáfora das armas dos militares que atingem e dilaceram a criação, a mentalidade criativa e até mesmo a vida dos poetas na conjuntura ditatorial - se afaste do poema, da boca e da mentalidade dos poetas. O expressivo desejo desse afastamento deve se dar pelo próprio viés da palavra e seu intenso reluzir. Assim, a força da materialidade da palavra e a força da garra de ferro são colocadas no poema como equivalentes, porém, nesse embate a palavra seria atribuída de tamanho furor a ponto de ser capaz de esfacelar a garra de ferro.

É oportuno observar, também, os versos que possuem vocábulos marcados em caixa alta e repetidos no decorrer do poema exposto acima, enfatizam o desejo de liberdade da palavra, do poema e da criação. Esse modo de Hilst abordar a censura da poesia, estando inserida em determinado contexto político condiz com a seguinte assertiva de Ostrower (2009) ao afirmar que:

\begin{abstract}
A maneira pela qual o indivíduo aborda e avalia certos problemas traduz, sem dúvida, algo de exclusivo de sua personalidade. Reflete anseios e conviç̧ões de caráter particular a partir de suas vivências também particulares. Reflete uma experiência imediata do viver, experiência que é nova e única para cada ser que vive e que é reestruturada cada vez com a própria vida (OSTROWER, 2009, p. 101).
\end{abstract}

A obra de arte é assim um acontecimento vivo de um momento singular da história e do sujeito que a elabora, de modo que sua impetuosidade possa agir 
objetivamente para com o contexto em que se está inserida. Nesse sentido, a vivacidade do poema reflete não somente o contexto da ditadura militar brasileira, mas também a personalidade combativa e crítica de Hilda Hilst preocupada com a condição do feminino na sociedade, assim como com a condição da poesia na sociedade opressiva da contingência política de 1974. Desse modo, a poeta pode ser considerada uma das raras contemporâneas, uma vez que "pode dizer-se contemporâneo apenas quem não se deixa cegar pelas luzes do século e consegue entrever nessas a parte da sombra, a sua íntima obscuridade" (AGAMBEN, 2009, p. 64). E, conforme foi demonstrado, Hilst se mostra capaz de enxergar as luzes e as sombras da época em que está inserida sem perder a coragem de lutar pela luminosidade da poesia.

\section{O poeta e seus desígnios}

Conforme exposto, a mentalidade criativa esteve contingenciada a criar devido àquele cenário político que colocava a matéria prima da expressão - o pensar e o falar de Hilda Hilst e de inúmeros outros poetas em risco, através da agressiva censura do governo, como exposto anteriormente. Para, além disso, saltar aos olhos nos poemas que se encontram mais a diante em "Poemas aos homens do nosso tempo" a atenção concedida à tarefa que caberia ao poeta, em virtude da acentuada alienação dos homens de seu tempo. Aquele é entendido como um sujeito em caráter de exceção no que concerne às artimanhas alienadoras devido à presença preponderante do que Hilst nomeia como "pássaro-palavra", o qual vive e reluz nos olhos e na boca do artesão da palavra, a fim de sustentar a crítica à política e a sociedade vigente e não se deixar cegar. 
Depois de ter sido feita uma extensa denúncia da privação da liberdade da palavra e da poesia, assim como de outros meios de comunicação, a voz lírica se dedica a evidenciar, por sua ótica, o comportamento dos homens e mulheres que também vivem e compartilham com ela o contexto sócio-histórico da ditadura militar governada por Emílio Médici de 1969 a 1974. Desse modo, a subjetividade lírica observa que os homens e as mulheres que a cercam pelas ruas em passos acelerados se atentam às "vitrines curvas" — metáfora dos aparelhos de televisão — as quais colaboram para aguçar e alimentar um desejo de consumo desenfreado, ocasionando a desumanização e a objetificação do homem:

\author{
XIII \\ Ávidos de ter, homens e mulheres \\ Caminham pelas ruas. As amigas sonâmbulas \\ Invadidas de um novo a mais querer \\ Se debruçam banais, sobre as vitrines curvas. \\ Uma pergunta brusca \\ Enquanto tu caminhas pelas ruas. Te pergunto: \\ E a entranha? \\ De ti mesma, de um poder que te foi dado \\ Alguma coisa clara se fez? Ou porque tudo se perdeu \\ É que procuras nas vitrines curvas, tu mesma, \\ Possuída de sonho, tu mesma infinita, maga, \\ Tua aventura de ser, tão esquecida? \\ Por que não tentas esse poço de dentro? \\ O incomensurável, um passeio veemente pela vida?
}

Teu outro rosto. Único. Primeiro. E encantada

De ter teu rosto verdadeiro, desejarias nada.

(HILST, 2017, p. 297).

Intrigada com essa movimentação "sonâmbula" dos indivíduos e percebendo a ausência de consciência dos atos praticados por estes, a voz lírica interrompe o caminho de seu interlocutor, o qual ela marca nos versos como um "tu" da enunciação, para 
questioná-lo mordazmente acerca da entranha, da constituição do homem no seu mais íntimo e o questiona, também, sobre o que se fez do poder que Ihe foi concedido. Para o psicólogo russo "a arte exige resposta, motiva certos atos e atitudes" (VYGOTSKY, 1999, p. 318). É exatamente em busca de suscitar uma resposta e uma ação palpável que a voz lírica questiona por que o interlocutor ainda não se aventurou nas profundezas do seu ser a fim de encontrar o seu rosto primeiro e verdadeiro, pois, caso estivesse preenchido de si mesmo, não haveria desejos fugazes e banais.

A leitura do poema XIII, exposto acima, indica que cabe ao poeta, em sua demasiada criticidade acerca do viver e do mundo, questionar os homens e as mulheres de seu contexto sócio-histórico sobre a essência do indivíduo. É ele o sujeito que, depois de muito observar, interrompe fluxo "natural" de outro sujeito para instigá-lo a "repensar o pensar", assim como ele. Nesse sentido, Ostrower assegura que "nessa busca de ordenações e de significados reside a profunda motivação humana de criar" (OSTROWER, 2009, p. 9). Em virtude da consideração desse desígnio do poeta há a possibilidade do leitor do poema preencher a forma pronominal que se encontra "vazia", o "tu" da enunciação. Isso ocorre, de acordo com Célia Pedrosa (2014), por meio de um "deslizamento estrutural", por meio do qual Hilda Hilst provoca os mesmos questionamentos aos seus leitores, sendo eles seus contemporâneos ou não.

Mais adiante, a voz lírica colocará em evidência como o contexto capitalista de acúmulo de bens, em consonância ao ideal da economia do progresso - tão propagada pelo governo militar de Emílio Médici - tem questionado o papel do poeta e da poesia na sociedade, sobretudo brasileira em detrimento de um ideal pragmático e utilitarista. Em virtude disso, a subjetividade lírica expõe e constrói uma crítica mordaz à sociedade ao 
dizer que enquanto o homem trabalha sua riqueza, o poeta trabalha o sangue, o ouro de dentro ainda tão pouco explorado:

\section{XVI}

Enquanto faço o verso, tu decerto vives.

Trabalhas tua riqueza, e eu trabalho o sangue.

Dirás que sangue é o não teres teu ouro

E o poeta te diz: compra o teu tempo

Contempla o teu viver que corre, escuta

$\mathrm{O}$ teu ouro de dentro. É outro o amarelo que te falo.

Enquanto faço o verso, tu que não me lês

Sorris, se do meu verso ardente alguém te fala.

O ser poeta te sabe a ornamento, desconversas:

"Meu precioso tempo não pode ser perdido com os poetas".

Irmão do meu momento: quando eu morrer

Uma coisa infinita também morre. É difícil dizê-lo:

MORRE O AMOR DE UM POETA.

$E$ isso é tanto, que o teu ouro não compra,

E tão raro, que o mínimo pedaço, de tão vasto,

Não cabe no meu canto.

(HILST, 2017, p. 299).

No poema acima, a subjetividade lírica lembra tanto o "tu" da enunciação quanto o leitor de apreciar atentamente o seu viver e o ouro que carrega dentro de si. Lembra-o que o dinheiro não compra o amor de um poeta, sentimento esse que nem sequer cabe totalmente em seus versos. Na leitura desses poemas, evidenciou-se que o desígnio do poeta é que sua poesia seja, constantemente, um "lembrete", uma "dose de humanidade" na vida do homem "sonâmbulo" para alertá-lo da necessidade e da importância de olhar atentamente para a essência do ser. Isso, mesmo que o poeta seja pelo interlocutor desprezado e tenha, equivocadamente, seus versos entendidos como motivos de desprezo e considerados como perca de tempo. 


\section{Considerações finais}

A subjetividade lírica de Hilda Hilst manifestada em "Poemas aos homens do nosso tempo" indica como o contexto sócio-histórico da ditadura militar vigente no Brasil entre 1964 e 1985 emerge na poesia de resistência e, consequentemente, deságua na crítica mordaz presente nesse conjunto de poemas que compõem a última parte de Júbilo, memória e noviciado da paixão (1974). Apesar dos atos de violência, de repressão, de tortura e de exílio em virtude da expressão política-ideológica que divergissem dos ideais políticos desse regime, a poeta assume um posicionamento axiológico e entre outros poemas que versam acerca da condição feminina, do amor e do erotismo, Hilst coloca sua enfática crítica aos homens do seu tempo, concedendo voz a uma subjetividade lírica que não se separa totalmente do seu eu empírico e é imbuída de acentuada consciência crítica.

Além disso, sua mentalidade criativa e, consequentemente, seu processo de elaboração poética é contingenciado a criar devido à barbárie, à proibição do voo do "pássaro-palavra" e a tantas outras atrocidades. Em virtude disso, Hilst cumpre através da arte da palavra - a qual passava por momentos de censura - o desígnio concebido ao poeta. Esse que deve provocar questionamentos, instigar o (re)pensar e colaborar para que os homens do seu tempo e de outros tempos em devir abandonem o comportamento apático, sonâmbulo e atente-se às suas entranhas, ao ouro mais valioso do que aquele que o sujeito tem sido estimulado a produzir e acumular. Esse estado de espírito, mobilizado pelo contexto histórico, social e político, pode ser considerado o principal motivador da criação e da tessitura literária de Hilda Hilst na busca pela garantia de liberdade - dos homens e da poesia. 


\section{Referências}

ADORNO, Theodor. Palestra sobre lírica e sociedade. In: Notas sobre literatura 1. Tradução Jorge de Almeida. São Paulo: Duas Cidades/Editora 34, 2003. p. 65-89.

AGAMBEN, Giorgio. O que é o contemporâneo? In: . O que é o contemporâneo? $\mathrm{E}$ outros ensaios. Tradução Vinícius Nicastro Honesko. Chapecó, SC: Argos, 2009. p. 55-73.

BAKHTIN, Mikhail. Estética da criação verbal. São Paulo: Martins Fontes, 1997. p. 215221.

COELHO, Nelly Novaes. A literatura feminina no Brasil contemporâneo. Língua e literatura, v. 16, n. 19, 91-101,1991.

HILST, Hilda. Júbilo, memória e noviciado da paixão. In: . Da poesia. São Paulo: Companhia das Letras, 2017.

OSTROWER, Fayga. Criatividade e processos de criação. Petrópolis, RJ: Vozes, 2009.

PEDROSA, Celia. Poesia, crítica, endereçamento. In: KIFFER, Ana; GARRAMUÑO, Florencia. (orgs.). Expansões contemporâneas. Literatura e outras formas. Belo Horizonte: Editora da UFMG, 2014. p. 69-90.

REZENDE, Maria José de. A ditadura militar no Brasil: repressão e pretensão de legitimidade. Londrina, PR: Eduel, 2013.

VYGOTSKY, Lev. Psicologia da arte. Tradução Paulo Bezerra. São Paulo: Martins Fontes, 1999.

Recebido em 13 de setembro de 2018.

Aceite em 11 de março de 2019.

\footnotetext{
'Referência ao poema "Mãos dadas", de Carlos Drummond de Andrade.
} 